\title{
'Change for the Better?'-making sense of housing association mergers in the Netherlands and England
}

\author{
Gerard van Bortel • David Mullins • Vincent Gruis
}

Received: 11 August 2008/Accepted: 21 May 2010/Published online: 12 June 2010

(C) The Author(s) 2010. This article is published with open access at Springerlink.com

\begin{abstract}
Mergers among housing associations have become a frequent phenomenon in both the Netherlands and England. The general literature on mergers highlights the need for research to consider the wider political and business environment, managerial motives and strategic choices, to adopt a process perspective and to evaluate outcomes in relation to competing definitions of goals and success criteria. This article applies these perspectives to consider drivers for and experience of housing association mergers in the Netherlands and England, competing motivations such as efficiency savings in relation to borrowing and procurement costs, improved professionalism and organisational capacity and external influence. We discuss the pace and motivations of mergers, the expected positive and negative effects, and actual outcomes. We focus on the impact of mergers on stakeholder satisfaction, housing production and operational costs. Based on our findings we discuss the implications for policies and practice in both countries. Our main conclusion is that the relationship between the size of housing associations and their performance is not straightforward. This is partly because large and small associations are generally trying to do different things in different ways and have contrasting strengths and weaknesses; thus judgements about whether mergers and concentration of ownership in third sector housing is a change for the better are dependent upon considerations of underlying purposes and success criteria.
\end{abstract}

Keywords Housing associations $\cdot$ Mergers $\cdot$ Motives $\cdot$ Process $\cdot$ Outcomes

G. van Bortel $(\bowtie)$

OTB Research Centre for the Built Environment, Delft University of Technology,

Delft, The Netherlands

e-mail: g.a.vanbortel@tudelft.nl

URL: http:॥www.otb.tudelft.nl

D. Mullins

CURS, University of Birmingham, Birmingham, UK

V. Gruis

Faculty of Architecture, Delft University of Technology, Delft, The Netherlands 


\section{Introduction}

Mergers have become a key feature of the restructuring of third sector housing in both the Netherlands and England. In the Netherlands the number of housing associations declined by more than $50 \%$ and the average number of dwellings per organisation increased from around 3,000 in 1997 to 5,600 in 2008. In England the average size of housing associations doubled in the past 10 years. In both countries there has been a process of concentration of ownership, which in some ways resembles the merger process in the private sector. However, a key difference from the private sector is that third sector organisations are not subject to 'hostile takeovers' since their shares are not traded on the market. Third sector organisations have no shareholders that could coerce their management into a merger.

A similarity between the housing associations and the private sector is that mergers frequently fail to deliver the promised results. Organisations often do not operate in a more efficient, effective or more customer-focused manner after a merger. Still the process of mergers in third sector housing is ongoing. So lacking shareholders and hostile take-overs that could drive this concentration in the not-for-profit housing sector, what are the forces underpinning this development and what are the impacts?

In this paper we want to explore the drivers and motivations for mergers among housing associations and the impact of mergers and organisational scale on their performance. We do this by presenting a preliminary analysis of the trends, patterns and implications of housing associations mergers based on work that has been conducted in parallel so far by researchers of third sector housing in England and the Netherlands. In Sect. 1 we discuss some key themes in the research literature on mergers in general to consider the position of mergers in third sector housing. Section 2 draws on research on the drivers, motives and anticipated effects of mergers in the two countries. Then it reviews in some detail existing and new evidence on outcomes of mergers in third sector housing, i.e. the impact on service delivery, operating costs and housing production (Sect. 3). In Sect. 4 we discuss possible explanations for unsuccessful mergers. In our conclusions (Sect. 5) we reflect on the implications of our findings for policy in different contexts, contrasting the high levels of policy steering in England with the much less regulated context in the Netherlands. We then suggest a potential research agenda that might enable comparative research to stimulate organisational and policy learning and promote change for the better in both countries.

\subsection{Methodological considerations}

This is a first attempt to bring together evidence on a complex process of organisational and sectoral change in two different housing systems with distinct legal and institutional contexts; although there has been earlier comparative work on related topics such as performance measurement (Walker and Van der Zon 2000). In the light of these differences, the findings are tentative and would benefit from further refinement in a comparative research study with a common methodology. However, institutional variations and problems associated with differing administrative datasets and definitions would still constrain comparison. Furthermore, since we are reliant mainly on interpreting findings from earlier studies in each country, as is often the case with such systematic evidence reviews, differences in findings may simply indicate the different research questions and methodologies adopted in the source studies. One small example of this is the emphasis in some of the English literature on the process of merger and the implications of choices made at an early stage in relation to strategic and cultural fit for long-term success (Jemison and Sitkin 
1986; Cowin and Moore 1996; Mullins 2000). This emphasis seems less prevalent in the Dutch literature and it is therefore difficult to make direct comparisons without comparable case study research. Nevertheless, it is apparent that similar questions are being asked about the drivers, outcomes and policy implications of merger activity (Audit Commission and Housing Corporation 2001; Davies et al. 2006; Van Veghel 1999; Cebeon, 2006). It is useful to review these prior to making some recommendations for a future agenda to accelerate learning through comparative research. In addition to published studies on mergers cited in this paper, our research base includes an analysis of previously unpublished performance data, ${ }^{1}$ interviews from a number of more general research projects ${ }^{2}$ and engagement with senior managers. ${ }^{3}$

\section{Mergers in third sector housing; learning from the wider research literature}

Mergers are nothing new, neither among commercial enterprises nor within the third sector. There is an extensive literature on the motives, process and outcomes of mergers in the private sector (Hubbard 1999; Jemison and Sitkin 1986), a key message of which is the high proportion of mergers that fail to increase shareholder value, partly as a result of the limited consideration given to post-merger implementation planning. Recent attention has been extended to mergers in the public and third sectors (Cornforth 1994; Cowin and Moore 1996) and similar stories of variable success and focus apply. Mullins (1999, 2000) has identified some relevant features of this literature for studying mergers in third sector housing. Four main features may be summarised here. The first is the need to consider the wider business and political environment in creating the climate for merger (Hubbard 1999). Private sector mergers tend to occur in waves reflecting disturbances or changes in the external environment usually related to the economic cycle. Analysis later in this paper shows similar patterns in the English housing association sector where policy and regulatory influences are strong drivers. The second is the need to consider managerial motives and strategic choices that influence how organisations respond to changes in the operating environment. For example, Singh (1971) argues that managers may be less interested in profits than in growth since size of firm can have a major influence on their own rewards. The consideration of managerial motives (Trautwein 1990) requires a critical approach to the proposals that housing associations produce for mergers ${ }^{4}$ and a broad perspective on organisational strategies including choices between different options (such as mergers, alliances and groups; see next paragraph). The third is the process perspective (Jemison and Sitkin 1986) which relates merger outcomes to decisions made at various stages of the process, particularly at an early stage, on strategic and cultural 'fit'; an over-emphasis on the former often leads to poorly planned integration processes and sub-optimal outcomes. Finally, there is a need to evaluate outcomes of mergers through close attention to the

\footnotetext{
$1 \mathrm{KWH}$-results of quality measurements gathered over several years, based on quality labels developed by KWH to assess landlord services, tenant and wider stakeholder involvement.

2 Delphi Panel study of English Housing Associations 1997-2004 (see Mullins 2006a for details, David Mullins' interviews with 20 Dutch HA directors 2007 (unpublished).

3 e.g. Mergers Masterclass at University of Birmingham December 2006, and work with National Housing Federation members 2004/2005.

4 Since 2005 English associations applying to the regulator for approval of mergers have been required to produce a business case setting out how the new structure will improve services, generate savings and how these savings will be monitored (Housing Corporation Chair's letter to HA board Chairs May 24, 2005).
} 
process and to the definitions of key success criteria (Cowin and Moore 1996) emerging from organisations themselves and from their operating environment. Thus our research on Dutch and English housing associations recognised that associations were often trying to do different things in different ways, whereby simple distinctions between success and failure are hard to make.

\subsection{A continuum of choices}

Returning to the question of strategic choice, Fig. 1 indicates that merger is just one on a continuum of options, including partnerships, alliances, group structures and full mergers. These options can all increase the scale of operations, but each has different implications for control, independence and transaction costs. Partnerships and alliances preserve the highest levels of independence for partner organisations but are difficult to control, resulting in high transaction costs and continuing instability (since partners may pull out at any time). Group structures are constitutional partnerships based on legal agreements but were at one time thought to preserve significant opportunities for independence while sharing central services and joint procurement. Mergers involve greater sacrifices of independence and the possibility of enhanced control to deliver greater efficiencies (e.g. through fuller functional integration and collapse of subsidiary governance) (Mullins and Craig 2005). The recent story of sector restructuring in England has largely been one of amalgamation through the group structure route, followed by fuller merger through 'streamlining' of governance and services delivery to create more integrated and unitary organisations (Pawson 2006; Mullins and Pawson 2010).

An important development in both countries is the creation through a series of 'megamergers' of a new set of third sector organisations operating on a much larger scale than ever before. In both countries the largest associations now own and manage in excess of 50,000 homes. It has been suggested that 'there is a real difference between managing an organisation of 30,000 and one of 50,000 homes', and that such organisations need new 'structures, methods, technology and mindsets' to operate effectively (London and Quadrant 2006). The emphasis on scale is somewhat ironic because housing associations in both England and the Netherlands started in the late nineteenth and early twentieth century as small-scale and locally based organisations (Malpass 2000; Ouwehand and Van Daalen 2002). Well into the

Fig. 1 Mergers and alliance options

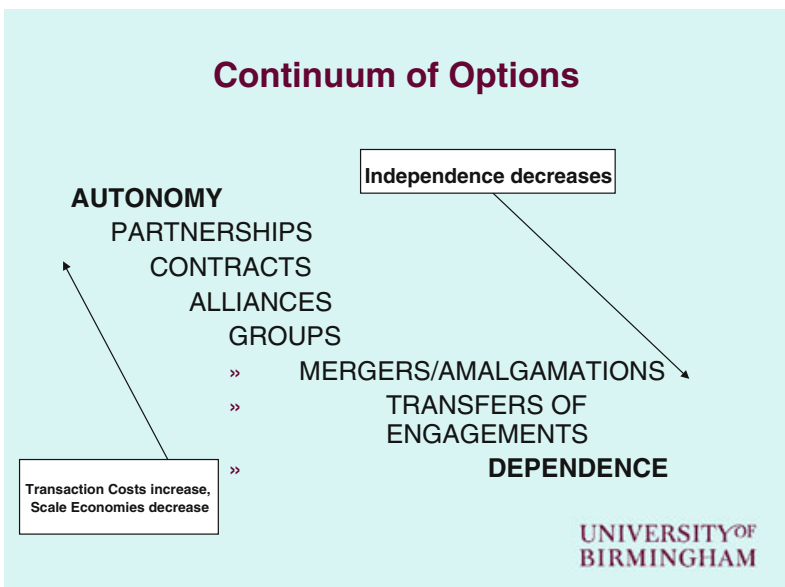


twentieth century English housing associations were seen to provide a smaller scale, an alternative associated with 'the rejection of mass models' (Kendall 2003, p. 138).

The role of housing associations in England and the Netherlands has considerable similarities. Both are now the main providers of social housing and often combine traditional landlord activities with social investments and community development. Dutch housing associations are financially more affluent, less regulated and more hybrid by combining third sector with commercial activities. Dutch housing associations are monopolists in the social housing sector, while in England social housing is also provided by local authorities which have much more of a 'mixed economy' of provision. In 2009 management of social housing in England was split into four almost equal shares: local authorities direct management (24\%), Arms Length Management Organisations managing homes for local authorities (23\%), traditional housing associations (27\%), and stock transfer housing associations (26\%) (Pawson and Mullins 2010).

\subsection{Change for the better?}

One key policy question has featured prominently in both countries: do large organisations perform any better than smaller ones and if so in what ways? This question has often been reduced to technical considerations of efficiency and cost, with sophisticated analyses attempting to compare costs of larger and smaller associations (CFV 2005; Indepen 2008). However, it is sometimes recognised that larger and smaller associations may be trying to do different things, and that their performance may therefore be very difficult to compare in a meaningful way. Lupton and Davies (2005) have suggested that rather than considering economies of scale we might consider economies of scope. Economies of scope consider the different scales at which activities (in contrast to the scale of the organisation) such as housing management, development and back office services are ideally undertaken (Chartered Institute of Housing (CIH) 2005). Moreover, Mullins (2006a) has suggested that organisational logics associated with increasing scale for efficiency reasons may conflict with logics concerned with promoting local accountability. Encouragingly large housing associations in both countries appear to be taking this conflict seriously and have been developing structural, cultural and governance solutions to the challenge to 'think globally but act locally'. For example, several larger Dutch associations have adopted structures with locally accountable management units of around 5,000 homes. In England the imperative to invest efficiency savings in service improvements has been stimulated by regulatory requirements for merger proposals, by concepts of corporate social responsibility and social return (Mullins and Nieboer 2008; Mullins and Sacranie 2009) and by increasing emphasis by the social housing regulator (until 2008 the Housing Corporation, now the Tenant Services Authority, TSA) on measuring social performance.

The pace of merger activity has been a highly visible and much discussed feature of both the Dutch and English housing association sectors over recent years. Long-term trend data for the two sectors indicates a similar direction of change, with high volumes of merger activity and a resulting increasing average size of housing associations in both countries (see Figs. 2, 3).

The different context for mergers in the two sectors is apparent from the available data. For example the number of registered housing associations in England has remained fairly constant since the sector has continued to grow through stock transfer. In direct contrast the number of Dutch housing associations has decreased by nearly $50 \%$ over the past 10 years. While the average size for all Dutch associations is more than 5,000 homes and the average 


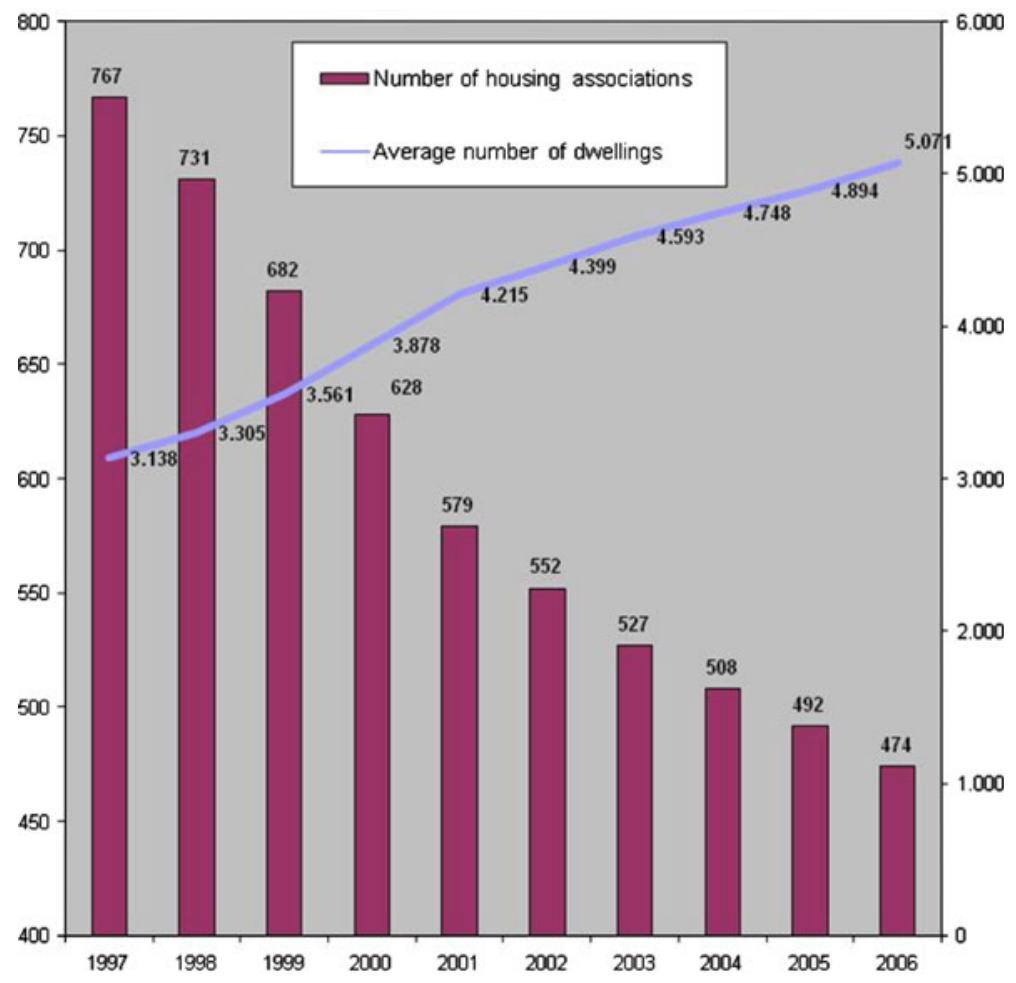

Fig. 2 Decrease in numbers and increase in average size of Dutch housing associations 1997-2006

Transfers of Engagements 1976 to 2005

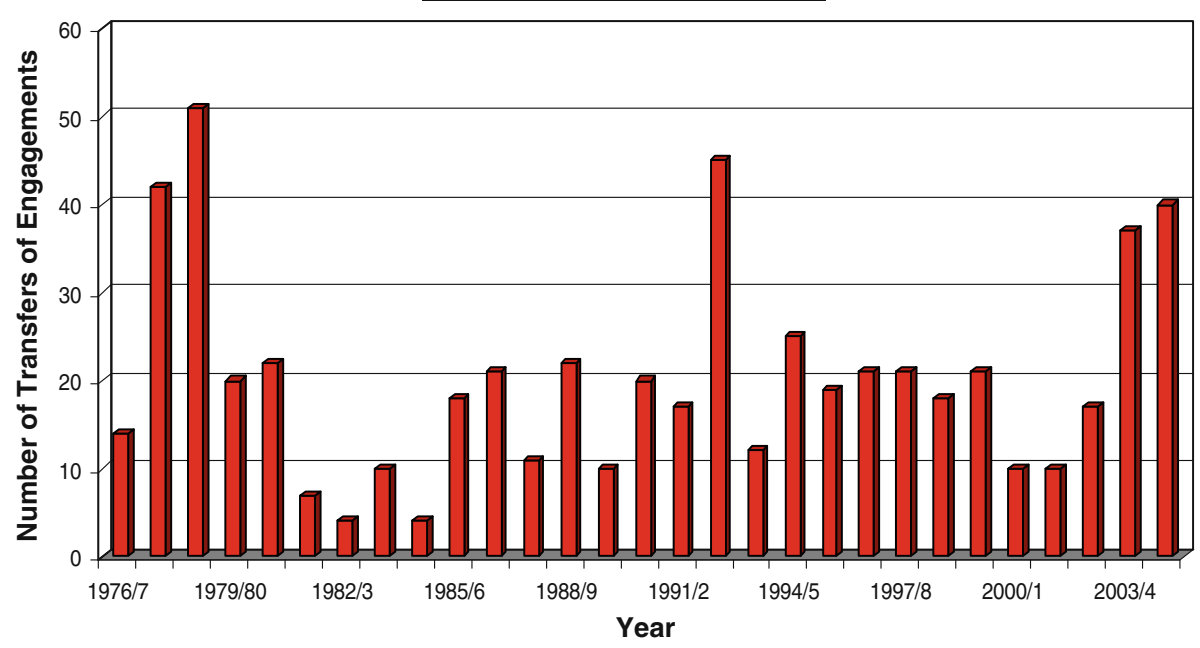

Fig. 3 Merger activity England 1976-2005 
English association is 1,420 , the largest associations in the two sectors are of a more comparable scale (50,000 England, 70,000 Netherlands).

Table 3 plots the time series of merger activity in England between 1976 and 2005. It shows a continuous flow of 'transfers of engagements' (i.e. mergers) averaging about $1 \%$ of the sector each year (Mullins 2000). Two peaks in activity reflected adjustments to legislative and funding changes: namely the introduction of public funding post-19741976; and the inauguration of the 'mixed finance' regime post-1988. In the later 1990s there was a shift in the form of restructuring with the emergence of group structures of associations and other charitable and non-charitable subsidiaries controlled by parent bodies. Initially stimulated by corporation tax changes, establishment of group structures was subsequently also motivated by other considerations including ring-fencing risky or specialist activities and accommodating local stock transfer subsidiaries (Audit Commission and Housing Corporation 2001). A further and more intense process of sector restructuring was triggered by 2004 reforms which concentrated development funding on the 70 or so 'best developing associations under the Housing Corporation's Investment Partnering procurement initiative' (Mullins 2006b, p. 9).

In the eight years to 2009, stock holdings of the typical English housing association grew by $50 \%$ (from 800 to 1,420 dwellings), while the proportion of national housing association stock in the ownership of the 20 largest providers grew from 26 to $29 \%$ (Pawson and Sosenko 2008). In England stock transfers from local authorities to housing associations have had an important impact on the institutional landscape. Over 200 transfer associations have been established, with stock holdings now exceeding those of the traditional housing association sector. Moreover, $40 \%$ of those set up as independent, stock transfer associations have subsequently established or joined together with others to form group structure arrangements. By 2007, over half of the transfer HAs operating as subsidiaries (over a quarter of all transfer HAs) were members of groups which also involved traditional (non-transfer) associations. (Pawson and Sosenko 2008). As a result, over $75 \%$ of the stock managed by the largest 50 English associations is now managed by groups including associations with origins in stock transfer from local authorities (Pawson and Mullins 2010). To a lesser extent stock transfer is also a feature of restructuring in the Netherlands where a White Paper in the early 1980s aimed to eliminate all municipal housing companies by 1996. In practice there were still 213 in 1990, falling to 23 by 2000 (Ouwehand and Van Daalen 2002). Almost all Dutch municipal housing companies have now been privatised into new independent housing associations or merged into existing social landlords. Some of the largest associations such as Ymere, with a housing stock of 80,000 in the Amsterdam region, originated from the municipal sector.

\subsection{Differences in policy context}

There are significant differences in the policy context in which this restructuring activity has been occurring in the two countries. Before the 1990s, Dutch housing associations were largely controlled by the government through regulations and financial arrangements. In the 1990s, however, the government diminished its direct financial support and replaced the prescriptive regulations by the principle of retrospective accountability. This new regulatory framework allowed the associations' a lot more administrative freedom, but it also meant a significant increase in their financial business risks (e.g. Gruis and Nieboer 2006). Consequently, housing associations have begun to adopt businesslike approaches in their management (e.g. Gruis and Nieboer 2004; Gruis 2008). Mergers among housing associations can be seen as part of this development and also as part of a wider trend of 
increased cooperation in various kinds of networks. Since the 1990s housing associations have set up several types of cooperation aimed at, for example, joint product development, treasury, finance and project development (including setting up project development companies jointly owned by two or more housing associations).

English housing associations have also been subject to a degree of marketisation and competition (Walker 2000). In particular, this has occurred through significant levels of private borrowing and reductions in the proportion of scheme costs funded by government, through cross-subsidies of rental housing from shared ownership and outright sales and a resulting emphasis on businesslike behaviour and strategic management (Mullins and Riseborough 2000; Mullins 2006a). However, English associations remain subject to strong regulation. Two of the most important drivers of merger activity in the sector have been regulatory intervention and a reduction in the number of investment partner associations directly funded by government (Mullins and Craig 2005). In England regulatory intervention has been the main driver for enforced mergers, there being no market mechanism for hostile take-overs. Enforced merger has long been the ultimate regulatory sanction in the case of failing associations. The increasing regulatory burden has also been a factor cited for merger, particularly by smaller associations (Mullins and Craig 2005). As in the Netherlands, there have been alliances and network co-operation in areas such as procurement and housing market renewal. Sacranie's concept of multi-layered merging captures the parallel processes of sectoral changes arising from blurring of state, market and third sector identities alongside organisational mergers to create new kinds of organisational cultures and governance models (Mullins and Sacranie 2008).

\subsection{Merger drivers, motives and anticipated benefits}

Researchers in both countries have attempted to establish why the trend towards increasing merger activity has occurred. We have reviewed the extent to which these accounts emphasise three main dimensions: external drivers inducing mergers as an organisational response; internal motives such as growth and succession planning; and anticipated benefits such as increasing professional expertise and ability to manage the regulatory burden. A fourth consideration, varying in the attention given to it, is the need to appraise varying options for achieving these anticipated benefits (e.g. the choice between alliance, group structures and mergers and the level of integration desired within the merger option) (Mullins and Craig 2005). Often such analyses combine these dimensions in a single set of factors.

In 1998, Van Veghel conducted a survey among Dutch housing associations to inquire about their motives for mergers (see Table 1). The three most frequent reasons for mergers stated in that survey are achieving a better market position because of the larger size, professionalisation and improving service delivery (Van Veghel 1999).

More recently, Cebeon (2006) conducted an in-depth analysis of the effects of mergers among 15 housing associations that had merged before 1 January 2002. As part of this analysis Cebeon asked what the objectives of the mergers were and whether the associations think the objectives have been achieved. In Table 2 we see that professionalisation and market position due to the increased size are still the most frequently mentioned objectives. Furthermore, these 15 housing associations seem to relate mergers more explicitly to their (re)development tasks and risks. In contrast to English associations, increasing efficiency is not a commonly stated motive for Dutch housing association mergers. 
Table 1 Motives for mergers mentioned by Dutch housing associations

\begin{tabular}{lcc}
\hline Motive & $n$ & $\%$ \\
\hline Better market position due to larger size & 32 & $(76)$ \\
Professionalisation & 31 & $(73)$ \\
Improving service delivery & 28 & $(67)$ \\
Improving financial continuity & 18 & $(41)$ \\
Better market position due to increased differentiation in housing stock & 18 & $(43)$ \\
A more efficient back office & 17 & $(23)$ \\
Matching investment tasks and means & 10 & $(24)$ \\
Efficiency in restructuring neighbourhoods & 10 & $(14)$ \\
Spreading risks of larger investment tasks & 6 & $(8)$ \\
Other reasons & 3 & 42 \\
Total & & \\
\hline
\end{tabular}

Source: Van Veghel (1998)

Table 2 Objectives and achieved results of mergers according to 15 Dutch housing associations

\begin{tabular}{lcc}
\hline Objective & $\begin{array}{c}\text { Stated as } \\
\text { objective }\end{array}$ & $\begin{array}{c}\text { Achieved } \\
\text { as result }\end{array}$ \\
\hline Increasing size to become a stronger player in the (local) housing area & 13 & 14 \\
Make further professionalisation possible & 12 & 15 \\
Being able to conduct a large task (restructuring, new housing development) & 11 & 13 \\
Increasing size to be able to handle larger risks & 11 & 11 \\
Better local or regional co-ordination because of concentration of ownership & 9 & 11 \\
Expansion of activities (new competences within the organisation) & 9 & 10 \\
Efficiency gains & 9 & 5 \\
Matching tasks and means (of 'rich' and 'poor' housing associations) & 6 & 7 \\
Other objectives & 2 & 4 \\
\hline
\end{tabular}

Source: Cebeon (2006)

In England a similar survey was undertaken by Mullins and Craig (2005) to inform responses of the National Housing Federation to an apparent acceleration in the pace and scale of merger activity in the English housing association sector. This study identified a continuum of merger and alliance options involving different trade-offs between independence and scale with different levels of transaction costs involved (Fig. 1).

In the 1990s Group Structures had become the most popular method to increase organisational scale. Group structures may be defined as formal associations of independent organisations in which one organisation, the parent, has ultimate legal control over the other 'subsidiary' organisations (Audit Commission and Housing Corporation 2001). One of the factors favouring groups was the ability to preserve apparently independent subsidiaries whilst benefiting from increased scale. After 2000 it became clear that independence was limited by regulatory requirements for parents to have control (Housing Corporation 2004) and later still increased emphasis on efficiency led to a move back to mergers with simpler streamlined structures as the preferred model. 
Mullins and Craig (2005) also made a distinction between external drivers and internal management motives and between the drivers for different types of partnership. Overall, there was remarkable consistency of view that a Government-led efficiency agenda and Investment Partnering had been the main drivers accounting for an increase in activity on all areas of the continuum over the past two years. For individual associations, people issues, especially the retirement of chief executives, was the main internal driver. Table 3 shows the most frequently mentioned drivers for each form of partnership.

\section{Outcomes}

\subsection{Impacts of mergers}

Assessments of the outcomes of mergers in the housing association sector have generally been rather inconclusive to date. This is partly because different types of questions have been asked, with a general tendency to seek evidence on financial benefits and cost savings rather than on a rounded assessment of impacts on financial and social performance. It also reflects a relative paucity of studies comparing the performance of different types and sizes of housing organisations though see for example Walker and Murie (2004). In this section we review existing evidence, but focus on new and emerging evidence highlighting the use of benchmarking data in the Dutch context.

Table 3 Main drivers and motives for different forms of mergers and alliances: England 2005

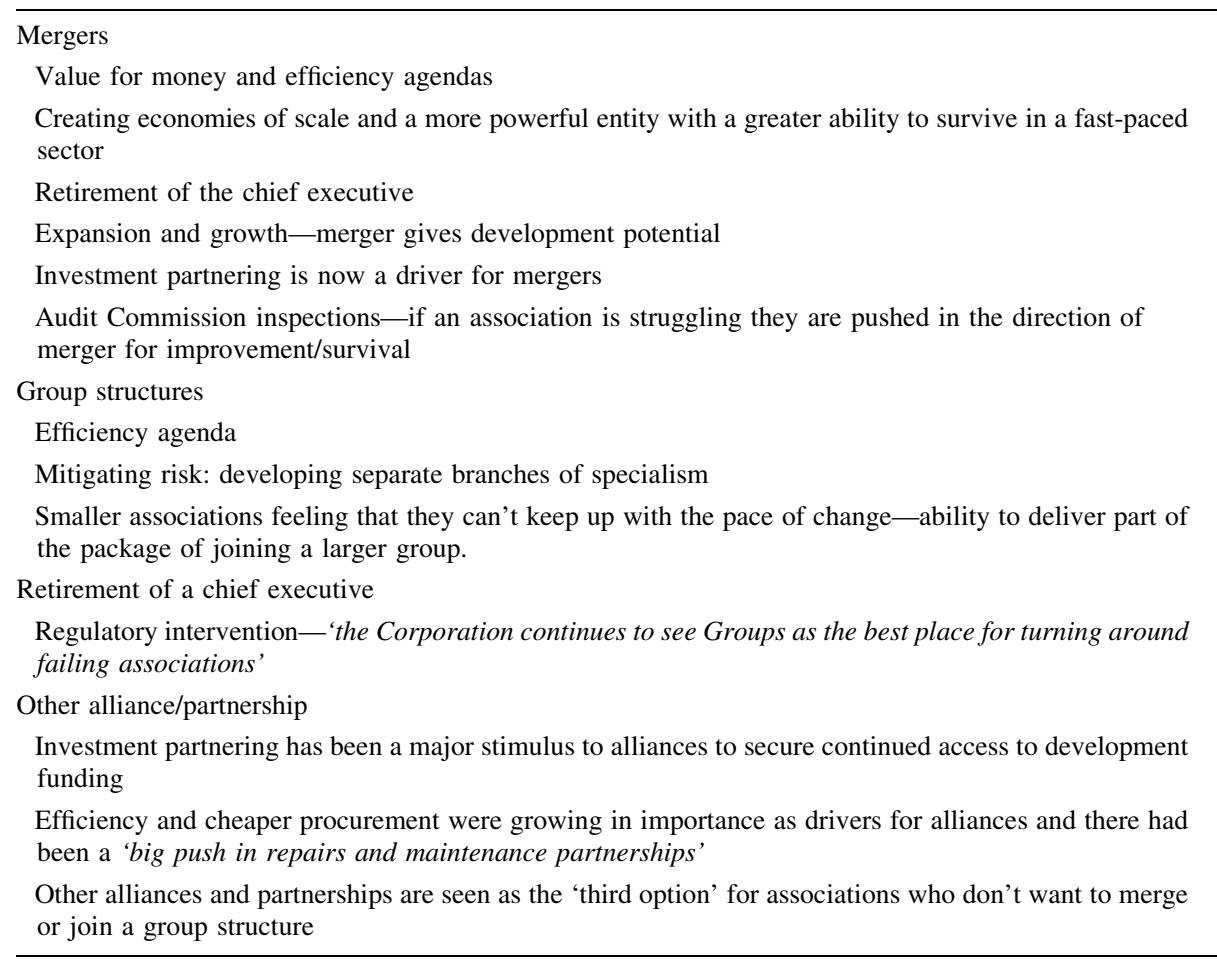


In England, an early study of group structures (Audit Commission and Housing Corporation 2001) was unable to find conclusive evidence of cost savings apart from those associated with corporation tax or procurement. However, it did express concerns that residents were being excluded from representation on the parent boards of the emerging groups. Later work by Lupton and Davies (2005) found that no general conclusions could be drawn about the correlation between scale and performance. They suggested instead that a focus on the desired social and other effects and on effective management is more important than the excessive emphasis currently placed on scale and structures. Most importantly they suggested that there is no such thing as 'one size fits all' for housing associations because different housing functions work best at different scales. This interesting finding is discussed further in our conclusion.

Later work by Davies et al. (2006) was critical of the ambition of associations when setting cost savings targets in their merger proposals (these were generally $1-2 \%$ of turnover or $1.5-3 \%$ of operating costs). In the view of Davies et al., more ambitious targets would have been appropriate and achievable. However, unpublished discussions by the present authors with experienced practitioners suggest that they sometimes felt it was better to 'aim low and overachieve'. This alternative view was influenced by the unanticipated costs frequently associated with mergers and by the increasing scrutiny of whether promised benefits were being delivered. ${ }^{5}$ Davies et al. also found that over half of the associations were failing to measure whether such savings targets were actually met, but recognised that 'measurement is inherently difficult given the dynamic nature of the business'. Their analysis of published performance indicators for 2005 suggested that groups had achieved savings in operating costs compared to other associations, but that outcomes on most other indicators such as relet times, repairs performance and tenant satisfaction were worse.

These studies appeared to influence the mood of organisational leaders involved in a Delphi panel study undertaken by one of the authors (Mullins 2006a). This study found that, paradoxically, most leaders expected a continued increase in merger and group structure activity, but few expected that such activity would result in cost savings for the associations involved. More recently, there has been a ramping up of regulatory expectations in relation to efficiency savings, close scrutiny of proposals (also referred to as 'business cases') submitted to support merger applications and more concerted attempts to monitor their achievement (signalled by a letter to all housing association chairs from the then Housing Corporation Chair, Peter Dixon in May 2005). It is possible that as a result of these changes clearer evidence will begin to emerge of such savings being delivered. For example, one of the authors is involved in a long-term evaluation of a major amalgamation of two large English groups to form an association of 50,000 homes. This organisation had set an initial savings target of $£ 2$ million for central services and a similar amount for a sub-group merger. It has adopted a balanced scorecard evaluation framework encompassing customer services, growth, influence and financial strength objectives. Later in this section we will explore new evidence emerging from the operating cost index concerning the impact of organisational scale on operating costs which suggests the emergence of a scale effect after 2005 (Indepen 2008).

In the Netherlands, the Central Housing Fund (CFV, Centraal Fonds Volkshuisvesting) has researched the subject from a primarily financial perspective (CFV 2005, 2006, 2007).

\footnotetext{
5 These discussions took place during a 'Mergers Masterclass' held at the University of Birmingham in December 2007, attended by the directors of several English associations and facilitated by two of the authors of this paper.
} 
The Housing Ministry (VROM) commissioned Cebeon (Centrum voor Beleidsondersteunend Onderzoek) to investigate the effect of mergers on social performance (Cebeon 2006). Cebeon's study focused on the qualitative effects of mergers, such as local performance agreements, regional and local commitment, effects on tenants, liveability, product differentiation, investment power, management costs and efficiency. The study concluded that mergers have a positive effect on the social performance of associations. An overview of those positive results has already been given in Table 2. Drawing mainly from Cebeon's report (2006), we can also mention the following potential (interrelated) negative effects:

- losing touch with (or giving less attention to) local governments, housing markets and neighbourhoods, particularly when mergers expand the distribution of the housing stock over multiple municipalities;

- becoming too strong in comparison to other associations and local stakeholders (monopolisation);

- becoming less accessible to (local) stakeholders due to the larger size (particularly when combined with a centralised decision-making structure) and due to the internal orientation during the first years after the merger;

- a lower level of service delivery due to decreased accessibility to individual clients;

- less efficiency due to a larger overhead and increased internal bureaucracy.

Data derived from the annual reports of housing associations and from interviews with association representatives give a picture of their results. But comparable data on how tenants and other stakeholders perceive the performance of associations is still scarce and fragmented. No similar data is available on the English social housing sector. Customer and stakeholder satisfaction assessments by the Dutch Kwaliteitcentrum Woningcorporaties Huursector $(\mathrm{KWH})$ indicate that mergers lead to a period of introspection, reflected in lower customer satisfaction scores immediately after a merger. The results fall in the first year but then rise sharply and even exceed the pre-merger level. Larger associations take longer to recover (see Fig. 4).

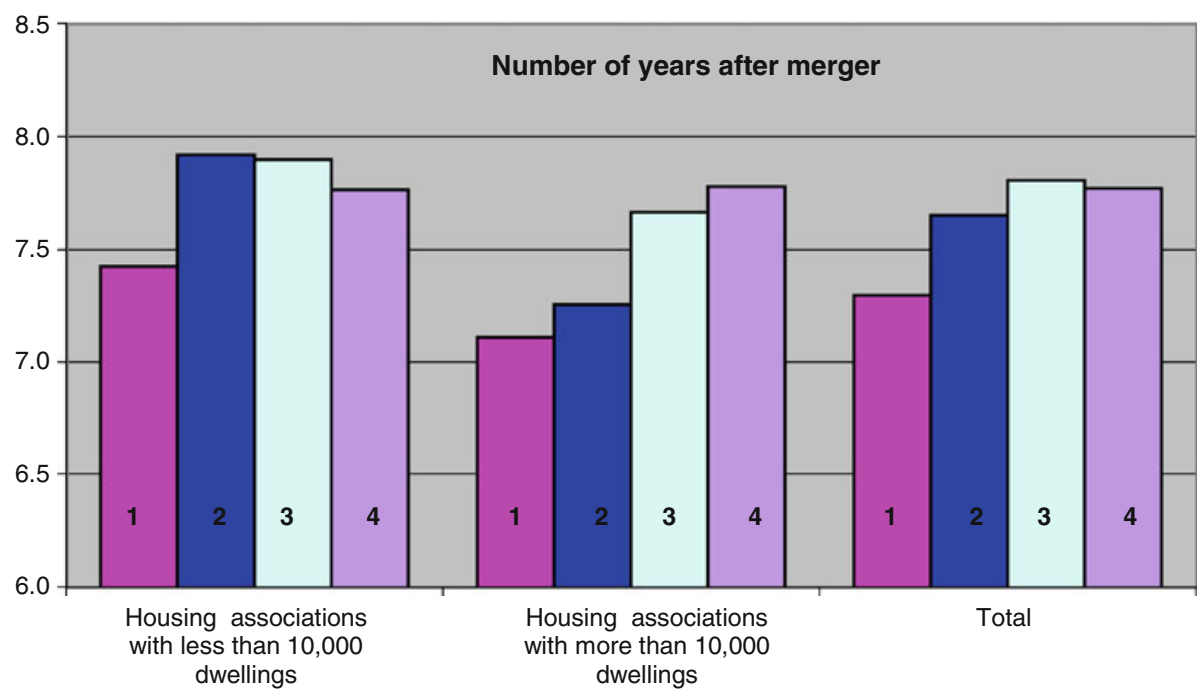

Fig. 4 Average KWH-Huurlabel scores in the post-merger period. Source: KWH 2007 


\subsection{Scale and the production of rented homes}

Apart from ratings by customers and stakeholders, the production of new homes is one of the main performance indicators for housing associations. In its sector survey for 2007, the CFV reports that, after reaching a record low in 2001, associations doubled their production of new rented homes to 24,700 units in 2006 (CFV 2007). However, the CFV also observes that, year on year, actual production is far below the associations' own forecasts, which were twice as high. Housing associations forecast 60,000 new rented homes in 2008, while the $\mathrm{CFV}$ - based on actual production in previous years - estimates that the annual production of rented homes will stabilise at around 30,000 units.

The extent to which associations contribute to new housing varies from association to association. For several years, the Housing Ministry (VROM) has published indexes showing the best-performing associations in terms of construction, sale and demolition.

If we look at the size of associations, it is the largest organisations that build, sell and demolish the greatest number of units. In 2006, the 56 associations with more than 10,000 units built 16,900 homes. The other associations built 7,700 units. In other words, the $12 \%$ largest associations built $69 \%$ of the new association-funded homes in the Netherlands. But the performance of large associations is less impressive when expressed as a percentage of units owned. With the exception of the 3 mega-associations with more than 50,000 homes, providers of rented social housing build between 30,000 and 50,000 homes-almost as many as the associations with less than 1,500 homes (see Fig. 5).

As noted earlier, English government funding for constructing new social and affordable housing has been focused on 74 large investment partners. Recently published data (Inside Housing, June 20, 2008) has confirmed that larger associations dominate the league table of new building. Of the top ten developers in 2008, none had fewer than 18,000 homes in management already; only two had fewer than 30,000 units and five already had more than 50,000 homes in management. Similarly it is mainly the larger associations that have the capacity to build housing for sale. So in the absence of a similar analysis we

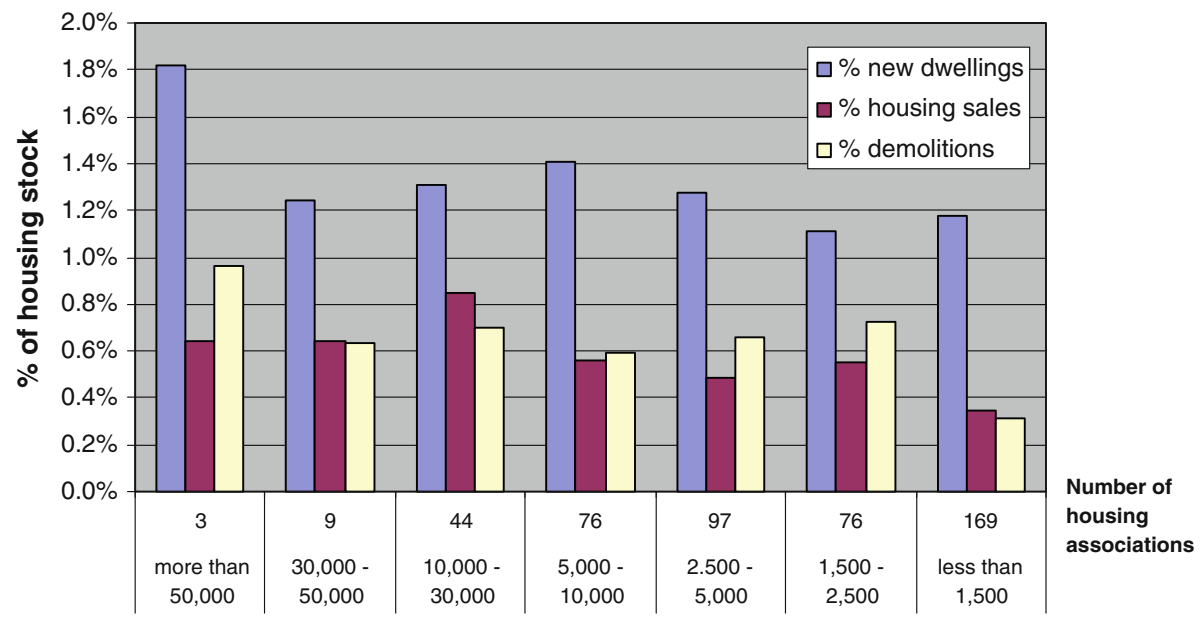

Size of housing associations in number of dwellings

Fig. 5 New housing production, sales and demolitions in 2006 in percentage of the housing stock of individual housing associations. Source: VROM 2006, adapation by authors 
would predict that similar conclusions could be generated about the general performance of larger and smaller English housing associations - that they do different things and have different strengths. Larger, more professional staffs improve compliance with corporate measures of performance, while greater financial capacity and asset strength contribute to higher new building activity and more construction for sale. However, on the down side merger processes can lead to dips in performance. Larger organisations can find it harder to achieve very high levels of customer satisfaction unless they are able to compensate for the loss of personalised relationships and trust that smaller landlords can engender.

\subsection{Scale and operation costs}

In addition to the societal outcomes, efficiency is also an important indicator for measuring the effects of expansion. Based on operating costs, it is difficult to defend the argument that expansion leads to increased efficiency. The study of the operating costs of associations (CFV 2005) shows that expenditure by large associations is considerably higher than that by small associations (Fig. 6).

Figure 7 shows that larger Dutch associations have higher operating costs. Mergers thus have less influence on cost levels. But this is not the full explanation. Why do large associations have higher operating costs? It would be easy, but perhaps not inaccurate, to attribute those costs to expensive head offices, high executive salaries and an excess of managers and corporate staff. Relatively speaking, large associations do indeed employ more people. In 2003, the associations with more than 4,000 units employed 10 FTEs for every 1,000 housing units, while associations with 600-1,800 units did their work with

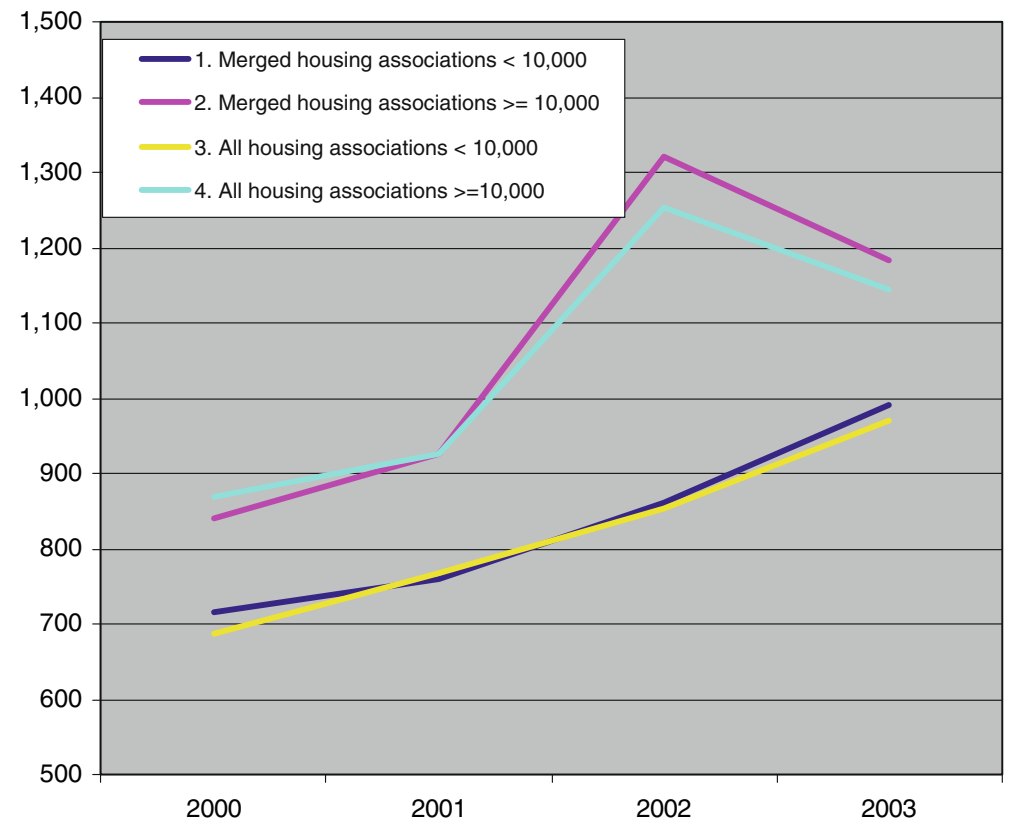

Fig. 6 Operating costs per dwelling (in euros). Source: CFV, survey of operating costs of housing associations, 2005 (adaptations by authors). Note: the sharp increase in operating costs per dwelling in 2002 was due to the fact that two large associations formed a provision for restructuring in that year 
Fig. 7 Process issues and outcomes England

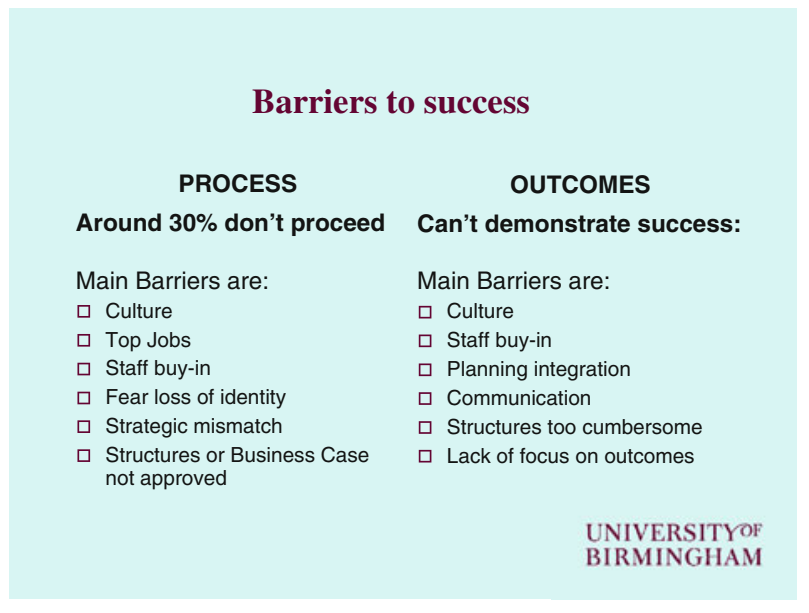

$25 \%$ fewer staff (CFV 2005). Part of the extra staffing capacity is allocated to propertydevelopment activities.

In its sector survey for 2006, the CFV reports that larger associations are better able to deliver their planned production of new dwellings. Nevertheless, a direct correlation between higher new production and higher net operating costs is not self-evident. Staffing costs relating to project development are usually absorbed in the all-in construction costs of the homes and therefore should not influence net operating costs. It appears that large associations carry out extra activities that cannot be absorbed in the all-in construction costs. We find indications of this in the follow-up study of operational costs published by the CFV in 2006. The study showed that associations with high operating costs have a higher ratio of staff to housing units. However, other operating costs have a greater influence, particularly the higher expenditure on accountants, external consultancy, marketing and communication, and liveability (e.g. investments in the public realm, social inclusion activities). The study concludes that the remuneration of top-level management does not contribute to the difference in operating costs. In its study, the CFV asked associations to break down their costs by activity. The responses showed that associations with high operating costs allocate a larger share of their wage costs to activities relating to social management and liveability.

In England as well, new evidence is emerging in relation to operating costs. This suggests that economies of scale are beginning to play a larger part in explaining variations in operating costs of English associations, particularly for traditional (i.e. non-stock transfer) associations.

In England a slightly different approach has been taken to calculating the operating cost efficiency of housing associations with more that 1,000 homes $^{6}$ in management and excluding 'specialist' associations (those with greater than $50 \%$ of housing for older people, supported and specialist housing). The Operating Cost Index (OCI) was introduced in 2004 and its methodology was amended in 2007 to enable 'meaningful comparisons between the operating costs of RSLs' (Housing Corporation 2007). It is presented as a tool for self-improvement to help associations understand their cost base and drivers in comparison to other associations.

\footnotetext{
${ }^{6}$ This threshold was introduced in 2007 and then applied to re-analysis of 2005 and 2006 data.
} 
The index uses data provided by associations in annual and quarterly returns to 'investigate the significance of various cost drivers, and only includes cost drivers that are found to be statistically significant and which are found to explain the majority of operating costs of RSLs' (these included the number of social and non-social housing units, house type mix, decent homes requirements and trends in costs versus inflation over time). Data has now been collected for three years and results for 2007 use a new method of calculation: actual cost as $\%$ of predicted cost. This is a far truer reflection of an index (a result of less than $100 \%$ suggests costs below that predicted, the converse being true for costs greater than $100 \%$ ).

The analysis (by Indepen Consultancy 2008) has consistently distinguished between operating costs of stock transfer and traditional associations. It shows different patterns for calculations with and without major repairs expenditure.

The first publication of results coincided with work by Lupton and Davies (2005) on mergers and scale, asking 'is bigger better'? They reported that 'an analysis of the OCI based on size found no strong evidence of economies or diseconomies of scale. If we consider the mean average performance (including major repairs) broken down by size, it shows that associations with less than 5,000 units have a higher average ranking than larger ones, but that the ranking of those between 5,001 and 7,000 is noticeably lower than the largest associations. If major repairs are excluded there are no clear differences based on size'.

The analysis by Indepen (2008) (using a new methodology and confining the analysis to associations with 1,000 or more homes) draws a rather different conclusion. 'There is evidence of economies of scale for English traditional associations on both measures of costs (including and excluding major repairs)'. For stock transfers there were scale economies if major repairs were excluded but not if they were included. 'Economies of scale had not been observed previously'.

Within its complex overall methodology, the Indepen study takes a relatively simple first step, comparing the number of social housing units to net operating costs. Using this simple coefficient alone they find that for traditional associations 'for every $10 \%$ increase in social housing units, net operating costs increase by $9.2 \%$, indicating economies of scale' (p. 22). For stock transfers the same coefficient indicates that 'for every $10 \%$ increase in social housing units net operating costs increase by $9.8 \%$, with no evidence of economies of scale' (p. 26).

This suggests to the outside non-technical observer that either the changed definitions had induced these new results or there had been an increased emphasis on delivering efficiencies in larger associations. The latter is evidenced by harder merger business case savings submitted to the Housing Corporation and the trend to streamline group structures to strip out bureaucratic and governance costs. Further possible explanations of patterns in the data suggested by Indepen include accounting treatment, timing and scale of major repairs, quality of outputs, and cost drivers not covered by the model.

\section{Unsuccessful mergers}

The literature on mergers indicates the importance of considering not just the motivations and external drivers but also the processes involved in brokering, negotiating and implementing mergers. Jemison and Sitkin (1986) argue that 'the acquisition process itself is a potentially important determinant of acquisition activities and outcomes' (p. 145). An important critique of much merger activity in the private sector, accounting for the rather 
limited success rate, is the emphasis on 'strategic fit' at the expense of 'organisational or cultural fit' (Porter 1987; Datta 1991). Strategic fit refers to the mutual goals and ambitions of the organisations prior to merger. The organisational and cultural fit are connected with the structure, systems, skills, management style, staff characteristics and shared values of the organisations that must be implemented after a merger to enable successful delivery of outcomes. This emphasis has also been found in the English housing association sector by Mullins (2000; see also Mullins and Craig 2005), who identified the typical stages of a merger process and noted that most guidance and attention had been given to strategic fit and pre-merger planning (e.g. National Housing Federation 1999).

Studies of critical success factors for mergers in both third sector (Cowin and Moore 1996) and profit-distributing sectors (Hubbard 1999) indicate that the most important stage of the process is after the deal has been done. Failure to plan for post-merger integration, inadequate consideration of organisational cultures and values of the partner organisations, and failure to keep the key stakeholders (staff, boards and customers) informed and involved in the change process are some of the most common causes of failed mergers.

Mullins and Craig (2005) explored the success rates of merger proposals. From expert interviews they estimated that $25-33 \%$ of proposed mergers fell by the wayside at various stages after their initiation. The main factors leading to abortive mergers were perceived differences in organisational cultures and failure to agree on who would be the Chair and Chief Executive of the new organisation. Following the business literature, which suggests that a high proportion of commercial mergers fail to deliver shareholder value, Mullins and Craig also explored some reasons why housing association mergers that proceed may not succeed. Again, culture was a major factor, together with post-merger integration issues such as planning, communication and staff buy-in.

Evidence of the reasons for mergers not proceeding is also available for the Netherlands, where Van Veghel (1999) asked housing association actors to indicate why a merger had not taken place in cases where mergers had been negotiated. As Table 4 shows, the most frequent reasons are related to differences in organisational cultures and company targets and the reluctance to give up the independence. It is interesting to note that customer factors such as tenant resistance and increased distance from clients were not mentioned by most respondents.

Table 4 Motives for not going through with a merger mentioned by Dutch housing associations

\begin{tabular}{lcc}
\hline Motive & $n$ & $\%$ \\
\hline Board of supervisors and/or director did not agree & 29 & $(48)$ \\
The culture of the organisations was too different & 28 & $(47)$ \\
The association did not want to lose its independence & 15 & $(25)$ \\
The company objectives were too different & 12 & $(19)$ \\
Resistance among employees & 8 & $(14)$ \\
The organisation of the companies was too different & 8 & $(5)$ \\
The distance to the clients would become too big & 3 & $(3)$ \\
Resistance among tenants & 2 & $(18)$ \\
Other reasons & 11 & 42 \\
Total & &
\end{tabular}

Source: Van Veghel (1998) 


\section{Conclusions}

In this paper we have explored the motives and outcomes of mergers in the Dutch and English housing association sectors. In both countries, mergers take place with a wide range of motivations, among which the desire to be able to create more output in terms of lettings, housing development and the variety of services seem common factors in both countries. The main distinctions we draw from the review of merger drivers evidence is the greater importance attributed to external drivers in the English context, reflecting the strength of regulator pressure. This is associated with the greater importance attached to efficiency than to factors such as market position and professionalisation, which drive the merger process in the more market-based Dutch context. Evidence on merger outcomes suggests that larger housing associations produce relatively more new homes, seem to be more capable of cooperation with societal partner organisations and offer a wider variety of services. Smaller housing associations perform relatively well in terms of service delivery and tenant participation (as appreciated by tenants). The evidence presented in this paper also suggests that smaller associations have relatively low operating costs, although the evidence from England is less conclusive. Our paper has also drawn attention to the importance of post-merger integration planning to merger success, noting the belated recognition of this by good practice guidance for the English third sector housing sector. It has shown the importance of cultural factors as barriers to the merger process and success in both countries, supporting the case for a greater balance between cultural fit and strategic fit in merger planning. Finally it has highlighted the greater recent attention to postmerger evaluation in the English context primarily in relation to regulatory drivers. In conclusion we would like to highlight some implications for policy and for strategic choices between a continuum of merger and alliance options. We also suggest some directions for future comparative research.

\subsection{Policy implications}

A key consideration in debating policy implications regards the different levers that are available to influence the policy directions we have observed.

In the Netherlands mergers have been seen as a response to freedom from state direction and the adoption of more businesslike behaviour by associations. Approval by the Housing Ministry is still required for mergers to proceed. Yet this is often a rather technical matter and there is little direct or indirect pressure by either CFV or VROM to make mergers happen. Dutch local authorities have relatively limited leverage over merger activity. They do exert influence on planning matters, regeneration schemes, and rent increases for higher quality properties, all of which may drive merger activity in certain situations.

In England the Housing Corporation had long declared its reluctance to intervene in the shape and structure of the sector. However over a long period regulatory intervention has been an important merger driver for failing associations. The regulatory burden (particularly arising from the inspection regime introduced in 2002) has been reported as a motive for merger even amongst associations not facing immediate regulatory intervention (Mullins and Craig 2005). Furthermore, since 2004 there has been an increasing steering of merger objectives as a result of the requirement to submit business cases to secure regulatory approval for mergers. The requirement to demonstrate clear customer benefits and efficiency savings has led to more focused proposals and to more streamlined structures capable of generating significant cost reductions. 
A final significant difference from the Dutch context is the ability to use public expenditure levers to influence organisational behaviour. Here, the most significant impact has come from the investment partnering regime. From 2004 on, it has limited the number of associations in direct receipt of a social housing grant, thereby encouraging other associations with development aspirations to merge or form alliances with the directly funded associations.

An underlying policy issue that is easily ignored is that in neither country are mergers in the third sector subject to the prospect of hostile takeovers, as found in the share trading parts of the private sector. This factor is significant, since it limits the ability of predatory or expansionist associations to realise acquisition targets. Moreover, it enables associations that may not be exploiting their assets to their full potential to continue to do so without the threat of external takeover.

\subsection{Scale, function and the continuum of partnership options}

Our main empirical conclusion is that the relationship between the size of housing associations and their performance is far from straightforward. This is principally because large and small associations are generally trying to do different things in different ways and have contrasting strengths and weaknesses. As we have seen in the Netherlands, smaller associations have more satisfied customers and tenant representatives, as well as lower operating costs. However, many small associations do not build new homes. The measurements for the KWH-Maatschappijlabel show that large associations are more effective in terms of relations with stakeholders and translating social expectations into business processes. In England larger associations have greater capacity to manage regulator compliance, and the regulation system itself has been a major driver of the trend toward increasing scale.

These findings clearly complicate judgements on whether the process of increasing scale and industry concentration through merger is a change for the better. Different organisations are trying to do different things, and some commentators have suggested that the optimum size may vary between activities. In England, Lupton and Davies (2005) have suggested that 'one size does not fit all' since different sizes are appropriate to different functions (Table 5).

The statements about size range are tentative and must be considered in the English context, in which housing associations manage fewer homes on average than associations in the Netherlands. However, it is clear that there is a minimum ideal size for activities such as property development, back-office, finance and improvements. By contrast, general housing management (e.g. rental and maintenance) have a maximum ideal size, above which the organisation becomes too distant from its customers. This differentiation is reflected in the attempts being made by many associations to find the best organisational

Table 5 Optimal size range for the activities of UK housing associations

\begin{tabular}{ll}
\hline Output & Optimal size range \\
\hline Housing management and maintenance & $1,000-5,000$ homes \\
Improvement and renovation & More than 5,000 homes \\
Project development & More than 7,000 homes \\
Full range of financial skills & More than 5,000 homes \\
Full range of back-office services & More than 10,000 homes \\
\hline
\end{tabular}

Source: Lupton and Davies, Chartered Institute of Housing (CIH) 2005 
structure, in cooperation with others or within their own organisation. They suggest a shift of focus from economies of scale to economies of scope. This relates to the added value for customers and stakeholders, and to finding the most appropriate organisational form (e.g. strategic alliance, joint venture or partnership geared to a specific service, business process, project or district).

In our earlier discussion of forms of merger and alliance (see Fig. 1) we identified a continuum of options with different combinations of scale, independence and transaction costs (Mullins and Craig 2005). One response to Lupton and Davies' (2005) conclusions on economies of scope would be to draw greater attention to alliances of independent organisations rather than to groups or fully integrated mergers. However, this option could involve higher transaction costs and difficulties in maintaining relationships as circumstances change.

\subsection{Future research directions}

This paper has provided the opportunity to exchange information and ideas about the meaning and trajectory of merger behaviour in two contrasting settings. While the research reported upon has explored similar themes, there have inevitably been difficulties in 'joining up' and comparing studies undertaken with different methods and purposes. However, from these studies we believe there is scope for further comparative work on housing association mergers in England and the Netherlands and would make the following suggestions.

Recent detailed analysis of sector restructuring in England (Pawson and Sosenko 2008) was not matched by any of the sources we located in the Netherlands. It would be useful to develop a similarly detailed descriptive account of the two sectors.

Work by KWH in the Netherlands provides a far more comprehensive picture of merger outcomes and the comparative performance of large and small associations across a broad field of performance goals than is currently available at aggregate level for English associations. It would be useful to harness benchmarking data to replicate such analyses and add to the rather ambiguous evidence emerging from the operating cost index studies (Indepen 2008).

Further work on the merger process seems critical given the findings of writers such as Jemison and Sitkin (1986) that early emphasis on strategic fit at the expense of cultural fit can plant the seeds of long-term adverse performance outcomes. Furthermore, it is important for this work to place emphasis on all stages of the process, including postmerger integration stages, where studies have again indicated that the seeds of failure are often harvested (Hubbard 1999). This approach is most likely to be achieved through case studies covering the life cycle of mergers and taking into account the impacts on a range of corporate aims and from the perspective of a variety of stakeholders. However, detailed case studies of the merger process and its outcomes are costly to undertake, are much less common and difficult to replicate. We believe, however, that studies taking into account multiple stakeholder and life cycle perspectives on organisational changes are most likely to generate knowledge that is of value in understanding and influencing these processes.

Given the differences in policy context and sector position clarified in this paper it would not be practical to attempt a controlled experiment comparison between case study organisations in the two countries. However, there would seem to be scope for a looser alliance of housing organisations and researchers interested in horizontal learning and involved in discrete long-term evaluations to share ideas on questions such as: 
- managing the tensions between scale and local accountability;

- developing new models to manage and measure social performance in large associations;

- developing organisational structures that enable large associations to be 'better neighbours' to local communities.

Acknowledgments The paper has benefited from the collaboration in 2007 and 2008 between the University of Birmingham, the OTB Research Institute for the Built Environment at the Delft University of Technology and the Architecture Department at the same university. It draws on a number of research studies, including unpublished studies and works in progress. This paper could not have been written without the cooperation of KWH, the Dutch Quality Centre for Housing Associations, which made available the measurement results from its 'KWH-Huur', 'KWH-Maatschappij' and 'KWH-Participatie' quality labels. This information has provided valuable insights into the performance of housing associations. Thanks to Hal Pawson and Filip Sosenko for providing access to their recent research on sector restructuring for the Housing Corporation (Pawson and Sosenko 2008) which provides a clear picture of the changing anatomy of the English sector. Finally we would like to thank the National Housing Federation for their support of earlier research on merger motives (Mullins and Craig 2005).

Open Access This article is distributed under the terms of the Creative Commons Attribution Noncommercial License which permits any noncommercial use, distribution, and reproduction in any medium, provided the original author(s) and source are credited.

\section{References}

Audit Commission and Housing Corporation. (2001). Group dynamics: Group structures and registered social landlords. London: Audit Commission and Housing Corporation.

Cebeon, (2006). Effecten fusies corporaties op maatschappelijke prestaties [Effects of mergers associations on social performance]. Cebeon: Amsterdam.

CFV (2005). Onderzoek bedrijfslasten woningcorporatie [Research operational costs HAs \#1]. Naarden: CFV.

CFV (2006). Vervolgonderzoek bedrijfslasten woningcorporatie [Research operational costs HAs \#2]. Naarden: CFV.

CFV (2007). Sectorbeeld 2007 [Sector overview Housing Associations 2007]. Naarden: CFV.

Chartered Institute of Housing (CIH). (2005). Is big really best or can small and friendly deliver? A briefing on the size, efficiency and effectiveness of housing associations. Coventry: $\mathrm{CIH}$.

Cornforth, C. (1994). Mergers between voluntary and third sector organisations: A change perspective. Pecs, Hungary: International Society for Third Sector Research Conference.

Cowin, K., \& Moore, G. (1996). Critical success factors for merger in the UK voluntary sector. Voluntas, $7(1), 66-86$.

Datta, D. K. (1991). Organisational fit and acquisition performance: Effects of post-acquisition integration. Strategic Management Journal, 12, 281-297.

Davies, A., Lupton, M., \& McRoberts, D. (2006). The bigger picture. The costs and benefits of groups, mergers and partnerships. Coventry: Chartered Institute of Housing.

Gruis, V. (2008). Organisational Archetypes for Dutch Housing Associations, Environment and Planning C (advanced online publication, printed version forthcoming).

Gruis, V., \& Nieboer, N. (Eds.). (2004). Asset management in the social rented sector; policy and practice in Europe and Australia. Springer/Kluwer: Dordrecht.

Gruis, V., \& Nieboer, N. (2006). Social housing investment without public finance: The Dutch case. Public Finance and Management, 6(1), 122-144.

Housing Corporation. (2004). Good practice note 11: Making groups work. London: Housing Corporation. Housing Corporation. (2007). The index of comparative operating cost. Briefing Note. London: Housing Corporation.

Hubbard, N. (1999). Acquisition strategy and implementation. Basingstoke: Macmillan.

Indepen. (2008). Operating cost index for housing associations in England. Study incorporating 2005/6 and 2006/7 data. Draft April 30, 2008. London: Indepen Consulting Limited.

Inside Housing, June 20th 2008. 
Jemison, D., \& Sitkin, S. (1986). Corporate acquisitions: A process perspective. Academy of Management Review, 11(1), 145-163.

Kendall, J. (2003). The voluntary sector. Comparative perspectives in the UK. Routledge: London.

London and Quadrant. (2006). Growing Up. Report of Future Shape of the Sector Commission. London: London and Quadrant Housing Trust.

Lupton, M. \& Davies, A. (2005). Is big really best-or can small and friendly deliver? Coventry: Chartertered Institute of Housing.

Malpass, P. (2000). Housing associations and housing policy. A Historical Perspective. Basingstoke: Palgrave.

Mullins, D. (1999). Managing ambiguity: Merger activity in the nonprofit housing sector. International Journal of Nonprofit and Voluntary Sector Marketing, 4(4), 349-364.

Mullins, D. (2000). Constitutional and structural partnerships: Who benefits? Housing research at CURS No. 8. Birmingham: Birmingham University.

Mullins, D. (2006a). Exploring change in the housing association sector in England using the Delphi method. Housing Studies, 21(2), 227-251.

Mullins, D. (2006b). Competing institutional logistics? Local accountability and scale and efficiency in an expanding non-profit housing sector. Public Policy and Administration, 21(3), 6-24.

Mullins, D. \& Craig, L. (2005). Testing the climate: Mergers and alliances in the housing association sector. Birmingham: University of Birmingham; http://www.curs.bham.ac.uk/publications/pdfs/Testing Climate.pdf.

Mullins, D. \& Nieboer, N. (2008). Comparing Dutch and English housing associations: Rational calculations and taken for granted assumptions. ENHR Dublin Conference Paper.

Mullins, D., \& Pawson, H. (2010). Housing associations. Agents of policy or profits in disguise? In D. Billis (Ed.), Hybrid organizations and the third sector challenges for practice, theory and policy. Basingstoke: Palgrave Macmillan.

Mullins, D., \& Riseborough, M. (2000). What are housing associations becoming? Final report of changing with the times project. Housing Research at CURS number 7. Birmingham: CURS University of Birmingham.

Mullins, D., \& Sacranie, H. (2008). Competing drivers of change in the regulation of housing associations in England: A multi-layered merging perspective. HSA Conference: York (unpublished).

Mullins, D. \& Sacranie, H. (2009). Corporate social responsibility and the transformation of social housing organisations: Some puzzles and some new directions. Paper presented at ENHR Conference, Prague June 2009 (unpublished).

National Housing Federation. (1999). Partnerships and practicalities. Making it Work. London: NHF.

Ouwehand, A. \& Van Daalen, G. (2002). Dutch housing associations. A model for social housing? DUP satellite. Delft University Press.

Pawson, H. (2006). Restructuring England's social housing sector since 1989: Undermining or underpinning the fundamentals of public housing? Housing Studies, 21(5), 767-783.

Pawson, H., \& Mullins, D. (2010). After Council Housing: Britain's New Social Landlords. Basingstoke, Palgrave Macmillan.

Pawson, H., \& Sosenko, F. (2008). Sector study: Restructuring. London: Housing Corporation.

Porter, M. (1987). From competitive advantage to corporate strategy. Harvard Business Review, 43-59.

Singh, A. (1971). Takeovers. Cambridge: Cambridge University Press.

Trautwein, F. (1990). Merger motives and merger prescriptions. Strategic Management Journal, 11, 239254.

Van Veghel, M. (1999). Fusies en samenwerking van woningcorporaties; een impressie van dynamiek en motieven [Mergers and cooperation between housing associations; an impression of dynamics and motives]. Delft: Delft University Press.

Walker, R. M. (2000). The changing management of social housing: The impact of externalisation and managerialisation. Housing Studies, 15(2), 281-299.

Walker, B., \& Murie, A. (2004). The performance of social landlords in Great Britain: What do we know and what does it show? Housing Studies, 19.2, 245-267.

Walker, R. M., \& Van der Zon, F. (2000). Measuring the performance of social housing organisations in England and the Netherlands: A policy review and research agenda. Journal of Housing and the Built Environment, 15(2), 183-194. 